\title{
Insulin sensitizer in prediabetes: a clinical study with DLBS3233, a combined bioactive fraction of Cinnamomum burmanii and Lagerstroemia speciosa
}

This article was published in the following Dove Press journal:

Drug Design, Development and Therapy

29 March 2016

Number of times this article has been viewed

\section{Asman Manaf' \\ Raymond R Tjandrawinata ${ }^{2}$ \\ Desi Malinda' \\ 'Department of Internal Medicine, Faculty of Medicine, University of Andalas, Dr M Djamil Padang Hospital, Padang, ${ }^{2}$ Dexa Laboratories of Biomolecular Sciences (DLBS), Cikarang, Indonesia}

Video abstract

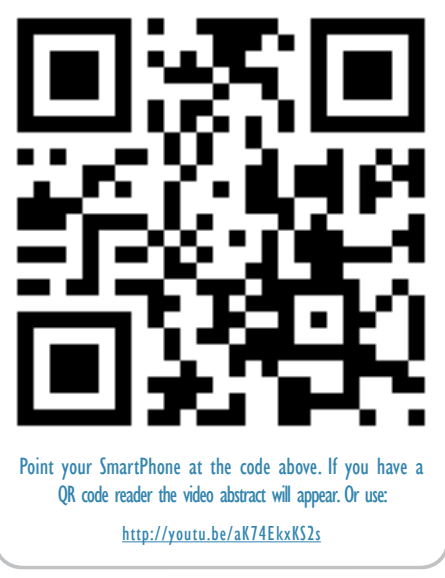

Correspondence: Raymond $R$ Tjandrawinata

Dexa Laboratories of Biomolecular Sciences (DLBS), Dexa Medica Group, Industri Selatan V, Block PP No 7, Kawasan Industri Jababeka II, Cikarang 17550, Indonesia

Tel +622 I 8984 I90।

$\mathrm{Fax}+622189841905$

Email raymond@dexa-medica.com
Background: The aim of this paper is to evaluate the efficacy and safety of DLBS3233, a novel bioactive fraction derived from Cinnamomum burmanii and Lagerstroemia speciosa, in improving insulin resistance and preserving $\beta$-cell performance in patients with impaired glucose tolerance (IGT).

Patients and methods: Eighty adult subjects with IGT, defined as 2-hour postprandial glucose level of 140-199 mg/dL, were enrolled in this two-arm, 12-week, double-blind, randomized, placebo-controlled preliminary study. Eligible subjects were randomly allocated to receive either DLBS3233 at a dose of 50-100 mg daily or placebo for 12 weeks. The study mainly assessed the improvement of homeostatic model-assessed insulin resistance (HOMA-IR), the 15-minute and 2-hour plasma insulin levels, and the oral disposition index.

Results: After 12 weeks, DLBS3233 improved insulin resistance better than placebo as reflected by a reduced HOMA-IR $(-27.04 \% \pm 29.41 \%$ vs $-4.90 \% \pm 41.27 \%, P=0.013)$. The improvement of the first- and second-phase insulin secretion was consistently greater in DLBS3233 group than placebo group $(-144.78 \pm 194.06$ vs $-71.21 \pm 157.19, P=0.022$, and $-455.03 \pm 487.56$ vs $-269.49 \pm 467.77, P=0.033$, respectively). Further, DLBS3233 also significantly better improved oral disposition index than placebo. No serious hypoglycemia, edema, or cardiovascular-related adverse events were found in either groups.

Conclusion: This study has shown that DLBS3233 at the dose of 50-100 mg once daily was well tolerated, and promisingly efficacious in improving insulin sensitivity as well as preserving $\beta$-cell performance in subjects with IGT.

Keywords: $\beta$-cell function, Cinnamomum burmanii, DLBS3233, Lagerstroemia speciosa, impaired glucose tolerance, insulin resistance

\section{Introduction}

A growing body of evidence shows that prediabetic condition is a risk factor for type2-diabetes and cardiovascular complications. ${ }^{1-3}$ Prediabetes is defined as impaired glucose tolerance (IGT) and/or impaired fasting glucose. ${ }^{2}$ IGT is associated with metabolic syndrome and is a strong predictor of atherosclerotic cardiovascular disease, whereas impaired fasting glucose is a much weaker predictor. ${ }^{4}$ There are no less than 300 million people with prediabetic condition worldwide, and the number is predicted to rise up to 418 million by 2025 . Every year, $2 \%-11 \%$ of the prediabetic population are converting to type-2-diabetics. ${ }^{1,2,4,5}$ Therefore, early intervention in the prediabetic stage is a valuable approach to reduce diabetes development and prevent related complications. ${ }^{3,6,7}$ 
Insulin resistance, $\beta$-cell dysfunction, and uncontrolled calorie consumption have been the crucial contributors to acute postprandial hyperglycemia and are the potential agents that convert prediabetes to diabetes. ${ }^{4,8,9}$ The acute postprandial hyperglycemia is responsible for glucotoxicity in the pathophysiology of type-2-diabetes even at the earlier stage (ie, prediabetes). ${ }^{10}$ Further in a vicious cycle, the impairment of $\beta$-cell function and exacerbation of insulin resistance due to glucotoxicity play a crucial role in the progression of diabetes and development of its cardiovascular complications., ${ }^{40}$

Interventions that preserve $\beta$-cell function and ameliorate insulin resistance have been proven to be most effective in preventing progression to diabetes. Many studies on lifestyle modification, including diet control and regular physical exercise, ${ }^{11-14}$ and pharmacological interventions using $\alpha$-glucosidase inhibitors, ${ }^{15,16}$ insulin sensitizers, such as metformin ${ }^{17}$ and thiazolidinediones, ${ }^{15,18}$ and incretin-mimetic agents, ${ }^{19}$ have been reported to have beneficial effects on inhibition of diabetes progression and complication. Indeed, lifestyle approach is safe, and in the long run (2-4 years), effectively reduces type-2-diabetes incidence by $28 \%-58 \% .{ }^{11-13}$ However, lifestyle interventions are notoriously difficult to maintain over a long period. Among the antidiabetic agents, thiazolidinediones, particularly pioglitazone, showed the most remarkable risk reduction (ie, up to $72 \%$ ) of IGT conversion to type-2-diabetes. ${ }^{3,4,18}$ However, long-term use of pioglitazone ( $>2$ years) was associated with discernible weight gain and edema, ${ }^{18}$ both of which are not favorable with respect to reducing cardiovascular risks. Because of these limitations of currently available interventions, there is a need to introduce a new substance for the treatment of prediabetes.

DLBS3233, a novel bioactive fraction derived from the plants Cinnamomum burmanii and Lagerstroemia speciosa, has previously been studied for its insulin-sensitizing activity. ${ }^{20,21}$ C. burmanii was obtained from Kerinci, Jambi, Indonesia, and L. speciosa from Cianjur, West Java, Indonesia. Both the plants have been identified by Herbarium Bogoriense, Research Center for Biology, Indonesian Institute of Sciences, with reference no 1261/IPH.1.02/If.8/XII/2009. A previous study demonstrated the safety and tolerability of the bioactive fraction DLBS3233 in healthy volunteers. ${ }^{22}$ An unpublished preliminary study by Suastika et al ${ }^{23}$ also demonstrated the favorable effects of DLBS3233 on glycemic control in newly diagnosed type-2-diabetes patients. In this study, DLBS3233 was preliminarily evaluated for its efficacy and safety in improving insulin resistance and preserving $\beta$-cell performance as well as for its clinical impacts in patients with IGT.

\section{Materials and methods}

\section{Subjects and study design}

This study was conducted in compliance with the Declaration of Helsinki, Good Clinical Practice, and relevant local regulatory requirements. The study protocol was reviewed and approved by the Independent Ethics Committee of Andalas University, Padang, Indonesia, prior to trial initiation. Written informed consent from each subject was obtained prior to screening.

Subjects with IGT, defined as 2-hour postprandial glucose (2h-PG) level of 140-199 mg/dL assessed by the oral glucose tolerance test (OGTT), ${ }^{2}$ were recruited from the clinic of Internal Medicine Department, Dr M Djamil Padang Hospital, and enrolled in this two-arm, prospective, double-blind, randomized, and controlled study. Male or female subjects aged 18-60 years were included. Pregnant or nursing women, subjects with diabetes mellitus, history of symptomatic coronary arterial disease, stroke, and any cardiovascular events, impaired liver function with serum alanine aminotransferase (ALT) $>2.5$ times the upper limit of normal (ULN), impaired renal function with serum creatinine $\geq 1.5$ times ULN, uncontrolled chronic diseases, and acute or chronic infections, and those undergoing treatment with systemic corticosteroids or herbal (alternative) medicines were excluded.

Eligible subjects were randomly allocated to receive either DLBS3233 or DLBS3233-matched placebo for a total of 12 weeks of therapy. On the day of enrollment (at baseline), in the morning after a 10 -hour overnight fast, subjects underwent a standard $75 \mathrm{~g}$ OGTT. Plasma glucose and insulin concentrations were determined from venous blood samples drawn at time points of 0,15 , and 120 minutes during OGTT. All clinical and laboratory examinations measuring the investigational product's efficacy were performed at baseline, Week 8, and Week 12 (end) of study treatment. In addition, fasting plasma glucose and $2 \mathrm{~h}-\mathrm{PG}$ were also measured at Week 4. Safety laboratory examinations (listed in last paragraph of Subjects and study design section) were performed at baseline and the end of study, while vital signs and body weight were measured at baseline and at intervals of 4 weeks over the study period. Occurrence of adverse events was observed during the study period.

Insulin sensitivity was quantified as a measure of hepatic insulin sensitivity during OGTT reflected by homeostatic model assessment - insulin resistance (HOMA-IR) index:

$$
\left(\text { HOMA-IR }=\frac{\operatorname{Ins}_{0}(\mu \mathrm{U} / \mathrm{mL}) \times \mathrm{Glc}_{0}(\mathrm{mmol} / \mathrm{L})}{22.5}\right) .
$$


In order to indicate $\beta$-cell performance, plasma insulin levels at 15 minutes (early phase) and 2 hours (second phase) during OGTT were measured, and the oral disposition index (DIo) of the early phase during OGTT:

$$
\left(\text { DIo }=\frac{\Delta \operatorname{Ins}_{0-15}(\mu \mathrm{U} / \mathrm{mL})}{\Delta \mathrm{Glc}_{0-15}(\mathrm{mg} / \mathrm{dL})} \div \text { HOMA- IR }\right)^{4,25}
$$

was also calculated. Further, other metabolic end points, such as reduction of 15-minute postprandial glucose and 2h-PG, glucose metabolic clearance rate (MCR) which was estimated from fasting and 2-hour plasma insulin and glucose levels during OGTT as described by Stumvoll et al (MCR $=13,273$ $\left.\left(0.00384 \times \mathrm{Ins}_{120}\right)-\left(0.0232 \times \mathrm{Ins}_{0}\right)-\left(0.463 \times \mathrm{Glc}_{120}\right)\right),{ }^{26,27}$ and fasting triglyceride level, were also measured. Safety end points were the following: body weight, vital signs, and electrocardiography; serum ALT, $\gamma$-glutamyl transferase, and alkaline phosphatase; and serum creatinine.

\section{Study treatment}

The study product, DLBS3233, a bioactive fraction (Dexa Laboratories of Biomolecular Sciences, PT Dexa Medica, Cikarang, Indonesia), contained natural components extracted from the Indonesian native plants: $C$. burmanii and $L$. speciosa. The details of preparation and extraction procedure as well as the phytochemical characterization of DLBS3233 were as previously described..$^{20,22}$ DLBS3233 was pharmaceutically formulated in the dosage form of capsules, each of which contained $50 \mathrm{mg}$ of the bioactive fraction.

The study medication was given at the dose of one capsule once daily for the first 4 weeks. Based on the evaluation of subjects' response to treatment at Week 4, subjects in both groups who were good responders, defined as those who achieved $2 \mathrm{~h}-\mathrm{PG}$ level $<140 \mathrm{mg} / \mathrm{dL}$ or a reduction of $2 \mathrm{~h}-\mathrm{PG} \geq 10 \%$ from baseline, remained at the same regimen, while the poor responders received a titrated dose of two capsules once daily, for the subsequent 8 weeks.

At each study visit, subjects were provided with education on lifestyle modification, such as regular exercise and dietary advice, by the assigned nutritionist. All subjects were advised to follow such a lifestyle modification throughout the study period. Any systemic medications other than the study product that were considered to interfere with the study evaluation, such as antidiabetic agents, systemic corticosteroids, or herbal (alternative) medicines, were not allowed to be taken during the study.

\section{Statistical analysis}

Efficacy analyses were carried out on intent-to-treat population, consisting of all patients who were randomized, exposed to at least one dose of the study product, and then attended at least one follow-up after treatment initiation. This included data from withdrawn subjects. Safety analyses were based on data of all patients who received at least one dose of study product.

All of the data are expressed as mean \pm standard deviation unless otherwise specified. Characteristic comparability between groups at baseline was assessed by independent $t$-test for continuous data, or by Pearson chi-square test for categorical data. Changes from baseline of HOMA-IR, plasma insulin levels, DIo, other measured metabolic parameters, vital signs, as well as body weight at each visit were analyzed individually between groups by independent $t$-test. In addition, each individual variable was analyzed within group by repeated-measures analysis of variance, followed by contrast analysis. Laboratory safety variables at baseline and end of study were statistically analyzed within group by paired $t$-test, and between groups by independent $t$-test. Throughout the analysis, the underlying distributional assumptions of the statistical models should have been met; otherwise, the corresponding nonparametric tests were used.

Adverse events were presented by system organ class and World Health Organization adverse reaction dictionarypreferred term. The number of events and subjects with each event were tabulated.

SPSS $^{\circledR}$ version 14.0 was used for the analyses.

\section{Results}

\section{Participants and baseline characteristics}

A total of 80 eligible subjects were enrolled in the study. Of them, 74 subjects $(92.5 \%)$ completed the study and were available for intent-to-treat analysis, with a mean age of $46.9 \pm 7.6$ and $50.5 \pm 7.3$ years, in DLBS3233 and placebo groups, respectively, and both groups were of female predominance ( $92.1 \%$ and $58.3 \%$, respectively). Six subjects $(7.5 \%)$ were withdrawn during the study. Of them, three subjects (two in DLBS3233 and one in placebo groups) were withdrawn due to noncompliance with the study protocol, one (in placebo group) due to pregnancy, one (in placebo group) due to adverse event (abdominal pain), and the remaining one patient (in placebo group) moved to another town and did not return for evaluation. Those six subjects could not be evaluated for efficacy and laboratory safety since they had no available posttreatment data.

With respect to cardiovascular risk factors and metabolic disorders, $50.0 \%$ and $63.9 \%$ of subjects in DLBS3233 and placebo groups, respectively, had hypertension; 31.6\% and $38.9 \%$, respectively, had dyslipidemia; and $18.4 \%$ and $13.9 \%$, respectively, were obese. All subjects received 
adequate treatment for such relevant concomitant illnesses during the study participation, with captopril and amlodipine as the predominant antihypertensive agents and simvastatin as the antihyperlipidemic agent used by study subjects in both groups. The mean blood pressures (BPs) were not significantly different between groups, with systolic
BP of DLBS3233 and placebo group at $125.3 \pm 16.0$ and $133.2 \pm 16.7 \mathrm{mmHg}$, respectively $(P=0.326)$, and diastolic $\mathrm{BP}$ at $81.3 \pm 10.4$ and $85.3 \pm 14.2 \mathrm{mmHg}$, respectively $(P=0.181)$. Baseline levels of the observed efficacy and laboratory safety parameters (Tables 1 and 2, respectively) were all comparable between groups.

Table I Baseline and improvement of metabolic parameters by DLBS3233 in comparison with placebo

\begin{tabular}{|c|c|c|c|c|c|}
\hline \multirow[t]{2}{*}{ Parameter } & \multicolumn{2}{|c|}{ DLBS3233 $(n=38)$} & \multicolumn{2}{|l|}{ Placebo $(n=36)$} & \multirow[t]{2}{*}{$P$-value ${ }^{\mathrm{b}}$} \\
\hline & Mean \pm SD & $P$-value ${ }^{a}$ & Mean \pm SD & $P$-value ${ }^{a}$ & \\
\hline $\begin{array}{l}\text { Fasting plasma glucose } \\
(\mathrm{mmol} / \mathrm{L}) \text { at baseline }\end{array}$ & $5.43 \pm 0.48$ & & $5.56 \pm 0.48$ & & NS \\
\hline Change at Week 8 & $-0.12 \pm 1.89$ & NS & $-0.02 \pm 0.54$ & NS & NS \\
\hline Change at Week 12 & $-0.35 \pm 1.81$ & NS & $-0.12 \pm 0.51$ & NS & NS \\
\hline $\begin{array}{l}\text { I5-minute-postprandial } \\
\text { glucose (mmol/L) at } \\
\text { baseline }\end{array}$ & $7.73 \pm 1.35$ & & $7.75 \pm 1.06$ & & NS \\
\hline Change at Week 8 & $-0.63 \pm 1.36$ & 0.007 & $-0.14 \pm 1.04$ & NS & NS \\
\hline Change at Week 12 & $-0.45 \pm 1.46$ & NS & $-0.19 \pm 1.14$ & NS & NS \\
\hline $\begin{array}{l}\text { 2-hour postprandial } \\
\text { glucose }(\mathrm{mmol} / \mathrm{L}) \text { at } \\
\text { baseline }\end{array}$ & $8.90 \pm 0.82$ & & $9.16 \pm 0.88$ & & NS \\
\hline Change at Week 8 & $-0.94 \pm 1.57$ & 0.001 & $-0.78 \pm 1.65$ & 0.012 & NS \\
\hline Change at Week 12 & $-1.24 \pm 1.60$ & 0.001 & $-1.06 \pm 1.92$ & 0.006 & NS \\
\hline $\begin{array}{l}\text { Fasting insulin (pmol/L) at } \\
\text { baseline }\end{array}$ & $84.38 \pm 41.7$ & & $76.16 \pm 56.41$ & & NS \\
\hline Change at Week 8 & $-23.39 \pm 31.81$ & $<0.001$ & $-19.49 \pm 53.78$ & 0.005 & NS \\
\hline Change at Week 12 & $-23.25 \pm 35.86$ & $<0.001$ & $-14.8 \pm 53.59$ & NS & NS \\
\hline $\begin{array}{l}\text { I5-minute-postprandial } \\
\text { insulin (pmol/L) at baseline }\end{array}$ & $435.27 \pm 223.19$ & & $378.08 \pm 167.22$ & & NS \\
\hline Change at Week 8 & $-133.80 \pm 198.96$ & $<0.001$ & $-95.42 \pm 204.91$ & 0.012 & 0.018 \\
\hline Change at Week 12 & $-144.78 \pm 194.06$ & $<0.001$ & $-71.21 \pm 157.19$ & NS & 0.022 \\
\hline $\begin{array}{l}\text { 2-hour postprandial } \\
\text { insulin ( } \mathrm{pmol} / \mathrm{L}) \text { at baseline }\end{array}$ & I,II $3.72 \pm 550.47$ & & $\mathrm{I}, 004.34 \pm 467.0 \mathrm{I}$ & & NS \\
\hline Change at Week 8 & $-36 \mid .4 I \pm 507.30$ & $<0.001$ & $-243.2 \mathrm{I} \pm 469.44$ & 0.033 & NS \\
\hline Change at Week 12 & $-455.03 \pm 487.56$ & $<0.001$ & $-269.49 \pm 467.77$ & 0.024 & 0.033 \\
\hline HOMA-IR at baseline & $3.00 \pm 1.76$ & & $2.76 \pm 2.28$ & & NS \\
\hline Change at Week 8 (\%) & $-21.91 \pm 28.21$ & 0.002 & $-13.63 \pm 33.62$ & 0.005 & NS \\
\hline Change at Week 12 (\%) & $-27.04 \pm 29.4 I$ & 0.001 & $-4.90 \pm 4 I .27$ & NS & 0.013 \\
\hline $\begin{array}{l}\text { Oral disposition index at } \\
\text { baseline }\end{array}$ & $0.5 I \pm 0.30$ & & $0.64 \pm 0.53$ & & NS \\
\hline Change at Week 8 & $+0.25 \pm 0.81$ & 0.012 & $-0.16 \pm 1.03$ & NS & 0.032 \\
\hline Change at Week 12 & $+0.06 \pm 0.35$ & NS & $-0.08 \pm 0.62$ & NS & NS \\
\hline $\begin{array}{l}\text { Estimated MCR } \\
(\mathrm{mL} / \mathrm{kg} / \mathrm{min}) \text { at baseline }\end{array}$ & $2.97 \pm 2.97$ & & $3.27 \pm 2.73$ & & NS \\
\hline Change at Week 8 & $+2.38 \pm 2.79$ & $<0.001$ & $+1.82 \pm 3.19$ & $<0.001$ & NS \\
\hline Change at Week 12 & $+2.85 \pm 2.79$ & $<0.001$ & $+1.70 \pm 3.05$ & 0.002 & 0.044 \\
\hline $\begin{array}{l}\text { Fasting triglyceride at } \\
\text { baseline }(\mathrm{mmol} / \mathrm{L})\end{array}$ & $1.49 \pm 0.70$ & & $1.39 \pm 0.63$ & & NS \\
\hline Change at Week 8 & $-0.30 \pm 0.63$ & 0.008 & $-0.15 \pm 0.51$ & NS & NS \\
\hline Change at Week 12 & $-0.32 \pm 0.62$ & 0.004 & $-0.17 \pm 0.38$ & NS & NS \\
\hline
\end{tabular}

Notes: ${ }^{a}$ Within-group comparisons, statistical significance compared to baseline. ${ }^{\circ}$ Between-group comparisons. NS, not statistically significant ( $\left.P>0.05\right)$. The changes in each parameter are the differences from their respective baseline levels. Negative values are reduction from baseline, while positive values, increase from baseline. Baseline: Week 0 , before treatment.

Abbreviations: SD, standard deviation; HOMA-IR, homeostatic model assessment - insulin resistance; MCR, metabolic clearance rate. 
Table 2 Effects on organ function and weight

\begin{tabular}{|c|c|c|c|c|c|}
\hline \multirow[t]{2}{*}{ Parameter } & \multicolumn{2}{|c|}{ DLBS3233 $(n=38)$} & \multicolumn{2}{|c|}{ Placebo $(n=36)$} & \multirow[t]{2}{*}{$P$-value ${ }^{b}$} \\
\hline & Mean \pm SD & $P$-value ${ }^{a}$ & Mean \pm SD & $P$-value ${ }^{a}$ & \\
\hline ALT (U/L) at baseline & $29.8 \pm 16.8$ & & $30.2 \pm 18.0$ & & NS \\
\hline Change at Week 12 & $-7.0 \pm 11.7$ & 0.001 & $-4.5 \pm 14.1$ & NS & NS \\
\hline$\gamma$-GT (U/L) at baseline & $26.8 \pm 26.5$ & & $28.0 \pm 14.6$ & & NS \\
\hline Change at Week 12 & $-4.8 \pm 14.7$ & NS & $-3.3 \pm 14.0$ & NS & NS \\
\hline AP (U/L) at baseline & $69.2 \pm 18.8$ & & $72.50 \pm 19.36$ & & NS \\
\hline Change at Week 12 & $-6.3 \pm 12.8$ & 0.001 & $-2.44 \pm|0.5|$ & NS & NS \\
\hline $\begin{array}{l}\text { Creatinine }(\mathrm{mmol} / \mathrm{L}) \text { at } \\
\text { baseline }\end{array}$ & $55.692 \pm 11.492$ & & $67.184 \pm 21.216$ & & 0.026 \\
\hline Change at Week 12 & $3.536 \pm 10.608$ & NS & $0.884 \pm 8.84$ & NS & NS \\
\hline $\begin{array}{l}\mathrm{SBP}(\mathrm{mmHg}) \text { at } \\
\text { baseline }\end{array}$ & $125.3 \pm 16.0$ & & $133.2 \pm 26.7$ & & NS \\
\hline Change at Week 12 & $-6.4 \pm 17.6$ & 0.035 & $-4.3 \pm 27.9$ & NS & 0.013 \\
\hline $\begin{array}{l}\mathrm{DBP}(\mathrm{mmHg}) \text { at } \\
\text { baseline }\end{array}$ & $81.3 \pm 10.4$ & & $85.3 \pm 14.2$ & & NS \\
\hline Change at Week 12 & $-4.7 \pm 12.0$ & 0.026 & $-3.3 \pm 15.3$ & NS & 0.020 \\
\hline Weight $(\mathrm{kg})$ at baseline & $67.39 \pm 11.13$ & & $68.06 \pm 10.36$ & & NS \\
\hline Change at Week 12 & $-1.85 \pm 2.92$ & $<0.001$ & $-2.23 \pm 1.88$ & $<0.001$ & NS \\
\hline
\end{tabular}

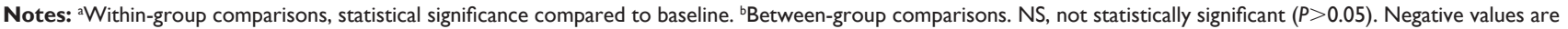
reduction from baseline, while positive values, increase from baseline.

Abbreviations: SD, standard deviation; ALT, alanine transaminase; $\gamma$-GT, $\gamma$-glutamyl transferase; AP, alkaline phosphatase; SBP, systolic blood pressure; DBP, diastolic blood pressure.

Sixteen subjects (42.1\%) in DLBS3233 group were poor responders and had their dose regimen titrated from 50 to $100 \mathrm{mg}$ at Week 4 till the end of study, while 15 (41.7\%) subjects in placebo group who met the nonresponders criteria also had their regimen titrated in order to maintain the blinding fashion. The remaining subjects were all maintained at the same regimen (50 mg daily) until the end of study.

\section{Improved insulin sensitivity}

Table 1 shows that fasting plasma glucose did not change in both groups. In contrast, fasting insulin in both groups decreased significantly. When fasting glucose and fasting insulin were combined as an index of hepatic insulin resistance (HOMA-IR), a more marked improvement was found in DLBS3233 group than in placebo group (Figure 1A). A significant reduction of HOMA-IR from baseline in DLBS3233 group was evident, from $3.00 \pm 1.76$ to $2.32 \pm 1.32$ $(P=0.002)$ and to $2.16 \pm 1.17(P=0.001)$ at Week 8 and Week 12 , respectively. In placebo group, a significant reduction from baseline was found at Week 8 (from 2.76 2.28 to $2.03 \pm 0.99, P=0.005$ ), but it was then diminished at Week 12 (to $2.28 \pm 1.24, P=0.158$ vs baseline). At the end of study, the percentage of HOMA-IR reduction from baseline was significantly greater in DLBS3233 group than that in placebo group $(-27.04 \pm 29.41$ vs $-4.90 \pm 41.27, P=0.013)$ (Figure 1A).

\section{Improved $\beta$-cell performance}

At baseline, an elevated first-phase insulin was observed at comparable level $(P=0.088)$ in both groups (Figure 1B). A significant improvement (normalization) of the insulin level was observed in DLBS3233 group, from $435.27 \pm 223.19 \mathrm{pmol} / \mathrm{L}$ at baseline, to $301.47 \pm 185.57 \mathrm{pmol} / \mathrm{L}(P<0.001)$ at Week 8 , and then to $290.48 \pm 132.44 \mathrm{pmol} / \mathrm{L}(P<0.001)$ at Week 12 . The changes observed in placebo group were not statistically significant $(P>0.05)$, from $378.08 \pm 167.22$ to $288.85 \pm 188.94 \mathrm{pmol} / \mathrm{L}$, and then to $306.87 \pm 184.92 \mathrm{pmol} / \mathrm{L}$, respectively. The sizes of improvement at Week 8 and Week 12 were also significantly greater in DLBS3233 group than that in placebo group (Figure 1B).

Aligned with the improvement of first-phase insulin level, the second-phase insulin level at Week 8 and Week 12 was also found to improve markedly in DLBS3233 group, from $1,113.72 \pm 550.47$ to $752.31 \pm 550.24 \mathrm{pmol} / \mathrm{L}(P<0.001)$, and then to $658.70 \pm 493.67 \mathrm{pmol} / \mathrm{L}(P<0.001)$, respectively. In contrast, we found no significant improvement in placebo group $(P>0.05)$, where the level went down from $1,004.34 \pm 467.01$ to $758.35 \pm 459.89 \mathrm{pmol} / \mathrm{L}$, and then to $734.86 \pm 517.54 \mathrm{pmol} / \mathrm{L}$, respectively. At Week 12, the 
A
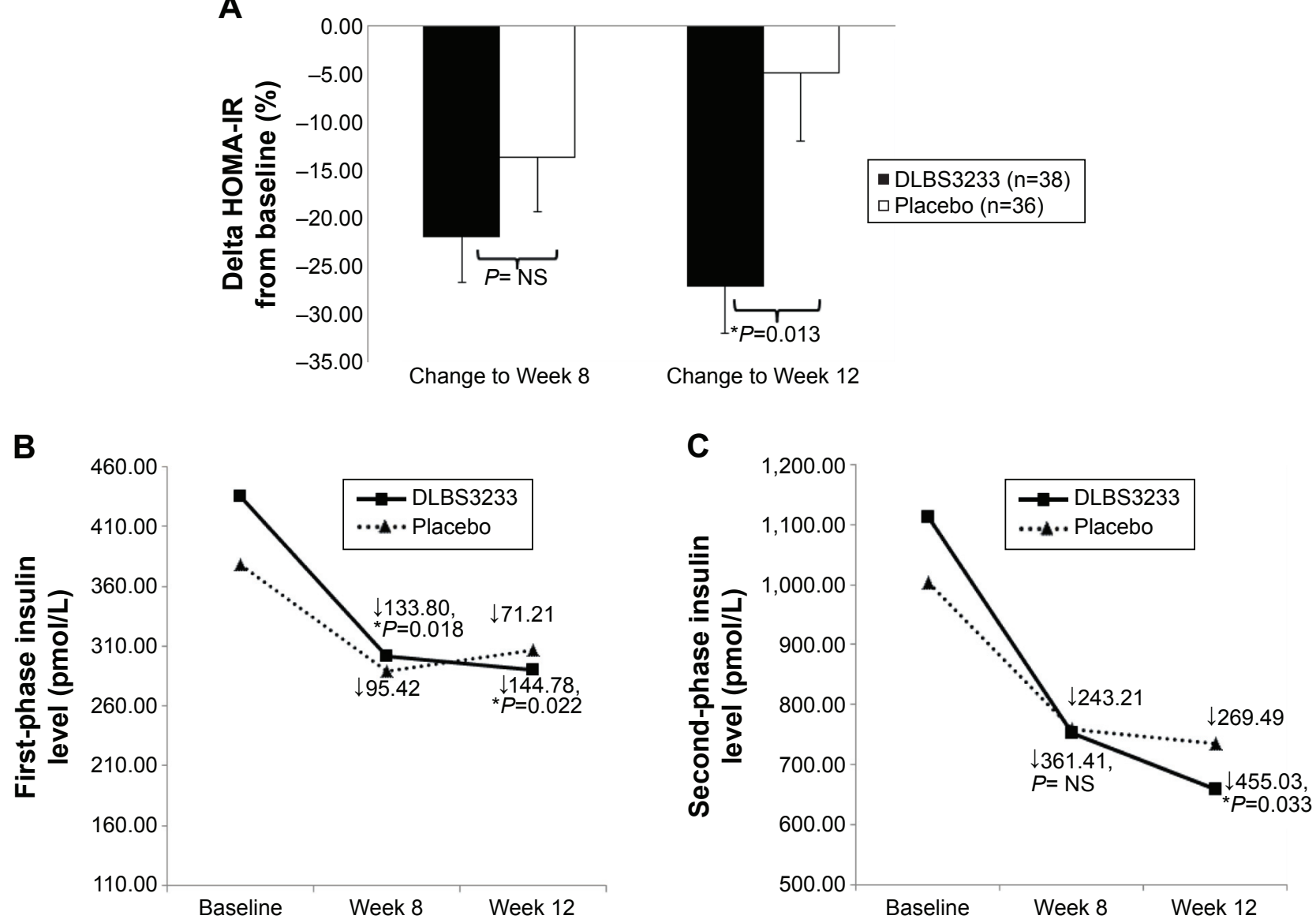

Figure I Improvement of insulin resistance and $\beta$-cell performance in each group.

Notes: (A) Percentage of HOMA-IR reduction from baseline. (B) First-phase insulin level (pmol/L) during OGTT. (C) Second-phase insulin secretion level (pmol/L) during OGTT. $P$-value resulted from statistical comparisons of delta from baseline, DLBS3233 vs placebo, individually at Week 8 and Week 12 . *A significant difference $(P<0.05)$ between groups was found. NS, not statistically significantly different $(P>0.05)$. If a between-group comparison was not significant $(P>0.05)$, the $P$-value was not mentioned, and only displayed as "NS". Error bars represent standard error of means.

Abbreviations: HOMA-IR, homeostatic model assessment - insulin resistance; OGTT, oral glucose tolerance test.

amount of improvement by DLBS3233 was significantly greater than that by placebo (Figure 1C).

The preservation of $\beta$-cell performance calculated as the DIo increased significantly only with DLBS3233 but was absent in placebo group (Table 1), with the increase at Week 8 being greater in DLBS3233 group than in placebo group $(0.25 \pm 0.81 \mathrm{vs}-0.16 \pm 1.03, P=0.032)$.

\section{Improved metabolic parameters: glucose MCR, postprandial plasma glucose, and triglyceride levels}

In line with the augmentation of insulin sensitivity (reduced HOMA-IR), we also found an increase of MCR of glucose at Week 8 and Week 12, in both groups (Table 1), with the enhancement of MCR at Week 12 being higher in DLBS3233 group than in placebo group $(2.85 \pm 2.79 \mathrm{~mL} / \mathrm{kg} / \mathrm{min}$ vs $1.70 \pm 3.05 \mathrm{~mL} / \mathrm{kg} / \mathrm{min}, P=0.044)$.
In terms of 15-minute postprandial glucose and $2 \mathrm{~h}-\mathrm{PG}$ during OGTT, despite the significant reduction observed in DLBS3233 group, the difference between groups was not statistically significant (Table 1).

A significantly lower level of triglyceride after 8 and 12 weeks of treatment was seen in DLBS3233 group, from $1.49 \pm 0.70 \mathrm{mmol} / \mathrm{L}$ at baseline, to $1.20 \pm 0.39 \mathrm{mmol} / \mathrm{L}$ $(P=0.008)$, and then to $1.17 \pm 0.43 \mathrm{mmol} / \mathrm{L}(P=0.004)$, respectively. In comparison with the placebo, the reductions of triglyceride level from baseline showed a trend in favor of DLBS3233 (Table 1).

\section{Additional beneficial effect on the BP}

Interestingly, after 12 weeks of treatment, a greater reduction of systolic and diastolic BPs was found with DLBS3233 (Table 2). In DLBS3233 and placebo groups, the systolic BPs were reduced from $125.3 \pm 16.0$ to $118.9 \pm 13.9 \mathrm{mmHg}$ 
$(P=0.035)$ vs $133.2 \pm 26.7$ to $129.0 \pm 18.3 \mathrm{mmHg}(P=0.600)$, and the diastolic BPs from $81.3 \pm 10.4$ to $76.6 \pm 9.4 \mathrm{mmHg}$ $(P=0.026)$ vs $85.3 \pm 14.2$ to $81.9 \pm 8.2 \mathrm{mmHg}(P=0.200)$. All study subjects with hypertension in both groups had controlled BPs at baseline and received adequate and generally similar antihypertensive treatment during the study.

\section{Safety to organ functions}

DLBS3233 did not adversely affect liver and renal function as demonstrated in Table 2. Reductions in ALT and alkaline phosphatase after 12-week treatment (at end of study) were found with DLBS3233, as compared to their respective baseline levels. No significant changes in serum creatinine level were observed in either groups. Body weight was significantly reduced in both groups, indicating that DLBS3233 was not associated with weight gain. Further, other than BPs, the changes of each of the safety parameters from baseline to the end of treatment were not significantly different between groups.

\section{Adverse events}

A total frequency of 180 adverse events occurred in 20 (of 40) subjects in DLBS3233 group and 19 (of 40) subjects in placebo group (Table 3). Of them, adverse events that were regarded possibly associated with the study product were dizziness, headache, tremor, and palpitation. No serious hypoglycemic events were found. All adverse events were mild in severity and subjects had fully recovered or stabilized at the end of study. No edema occurred in either groups. Serious and severe cardiovascular-related adverse events were also not found.

\section{Discussion}

Patients with IGT are at high risk of developing type-2-diabetes since they already have insulin resistance and may have lost a large amount of $\beta$-cell function. ${ }^{4}$ IGT is also a strong predictor of metabolic syndrome and arteriosclerotic heart disease. Approximately $22 \%$ of individuals with IGT have at least one microvascular complication..$^{28,29}$ Therefore, nowadays, IGT has been attracting more attention for primary prevention of type-2-diabetes and its macrovascular complications. A growing body of evidence demonstrates that both nonpharmacological and pharmacological interventions in IGT have been effective in preventing or delaying macrovascular complications and conversion to overt diabetes. Our study preliminarily demonstrated the benefits of DLBS3233 in improving insulin resistance and preserving $\beta$-cell performance in subjects with IGT.
Table 3 Adverse events

\begin{tabular}{|c|c|c|}
\hline \multirow[t]{2}{*}{ Adverse events } & $\begin{array}{l}\text { DLBS3233 } \\
(n=40)\end{array}$ & $\begin{array}{l}\text { Placebo } \\
(n=40)\end{array}$ \\
\hline & \multicolumn{2}{|c|}{$\begin{array}{l}\text { Number of events (number } \\
\text { of subjects with event) }\end{array}$} \\
\hline \multicolumn{3}{|c|}{ Central/peripheral nervous system } \\
\hline Anxiety & $3(2)$ & 0 \\
\hline Appetite exaggerated & $9(7)$ & $10(7)$ \\
\hline Dizziness & $16(10)$ & $10(7)$ \\
\hline Drowsiness & 0 & $\mathrm{I}(\mathrm{I})$ \\
\hline Headache & $8(6)$ & $2(2)$ \\
\hline Insomnia & $I(I)$ & $\mathrm{I}(\mathrm{I})$ \\
\hline Local coldness & $\mathrm{I}(\mathrm{I})$ & 0 \\
\hline Tremor & $9(5)$ & $2(2)$ \\
\hline Vertigo & $2(1)$ & 0 \\
\hline \multicolumn{3}{|l|}{ Cardiovascular system } \\
\hline Increased blood pressure & 0 & $3(3)$ \\
\hline Palpitation & II (6) & $4(4)$ \\
\hline \multicolumn{3}{|l|}{ Ophthalmologic system } \\
\hline Blurred vision & $I(I)$ & 0 \\
\hline \multicolumn{3}{|l|}{ Ear, nose, and throat system } \\
\hline Ear ache & $I(I)$ & 0 \\
\hline \multicolumn{3}{|l|}{ Respiratory system } \\
\hline Coughing & 0 & $\mathrm{I}(\mathrm{I})$ \\
\hline Dyspnea & $\mathrm{I}(\mathrm{I})$ & 0 \\
\hline Laryngitis & $I(I)$ & 0 \\
\hline Pharyngitis & 0 & $I(I)$ \\
\hline \multicolumn{3}{|l|}{ Gastrointestinal system } \\
\hline Abdominal pain & 0 & $2(2)$ \\
\hline Appendicitis & $\mathrm{I}(\mathrm{I})$ & 0 \\
\hline Constipation & $I(I)$ & $\mathrm{I}(\mathrm{I})$ \\
\hline Diarrhea & $2(2)$ & 0 \\
\hline Gastritis & 0 & $\mathrm{I}(\mathrm{I})$ \\
\hline Nausea & $2(2)$ & $\mathrm{I}(\mathrm{I})$ \\
\hline \multicolumn{3}{|l|}{ Reproductive system } \\
\hline Menstrual disorder & $3(2)$ & 0 \\
\hline \multicolumn{3}{|l|}{ Urinary system } \\
\hline Polyuria & 0 & $2(1)$ \\
\hline Oliguria & 0 & $\mathrm{I}(\mathrm{I})$ \\
\hline \multicolumn{3}{|l|}{ Musculoskeletal system } \\
\hline Myalgia & $4(4)$ & $4(4)$ \\
\hline \multicolumn{3}{|l|}{ Skin and appendages system } \\
\hline Acne & $I(I)$ & $I(I)$ \\
\hline Dermatitis & 0 & $2(1)$ \\
\hline Pruritus & $2(2)$ & $2(2)$ \\
\hline Hyperpigmentation & 0 & $I(I)$ \\
\hline \multicolumn{3}{|l|}{ Body as whole - general } \\
\hline Feeling unwell & $\mathrm{I}(\mathrm{I})$ & 0 \\
\hline Fever & I (I) & $3(3)$ \\
\hline General weakness & $15(9)$ & $8(6)$ \\
\hline Influenza-like symptoms & $\mathrm{I}(\mathrm{I})$ & 0 \\
\hline Leg pain & $2(2)$ & $\mathrm{I}(\mathrm{I})$ \\
\hline Pain & $I(I)$ & 0 \\
\hline Diaphoresis & $7(4)$ & $5(4)$ \\
\hline Total & $108(20)$ & $70(19)$ \\
\hline
\end{tabular}

Note: One subject might have more than one adverse event. 
In this study, subjects were diagnosed to have IGT based on the OGTT. $\beta$-Cells respond to an increment in glucose $(\Delta \mathrm{Glc})$ with an increment in insulin $(\Delta \mathrm{Ins})$, and this response is modulated by the severity of insulin resistance. Therefore, $\beta$-cell performance is more appropriately measured as a function of both insulin secretory response to glucose stimulus and insulin resistance. Simply measuring plasma insulin response to assess $\beta$-cell function may be misleading. ${ }^{4}$ In our study, we included both the insulin level and insulin resistance to estimate $\beta$-cell performance as reflected by the DIo. After 12 weeks of treatment, the insulin resistance was ameliorated in DLBS3233 group as demonstrated by a significant HOMA-IR reduction (Figure 1A).

Our study showed that augmentation of insulin sensitivity by DLBS3233, through its insulin-sensitizing properties, ${ }^{20,21}$ was finally compensated by a significant reduction - which can also be translated as normalization - of the first- and second-phase insulin levels as shown in DLBS3233-treated group after 8 and 12 weeks. This result indicates an insulinsparing effect of the treatment. A former study by $\mathrm{Kahn}^{30}$ showed a similar finding that when insulin sensitivity was improved by exercise, a reduced insulin secretion was observed. Another study by Ferrannini et $\mathrm{al}^{31}$ and Gastaldelli et $\mathrm{al}^{32}$ demonstrated that improvement of insulin sensitivity by insulin sensitizers was associated with a decline in plasma insulin response. The decline in the first- and second-phase insulin response has been generally interpreted to reflect the normal compensatory response of $\beta$-cells to the improvement of insulin sensitivity and/or reduced plasma glucose level.

Guldstrand et $\mathrm{al}^{33}$ demonstrated that the reduction in insulin secretion was quantitatively not as prominent as the increase in insulin sensitivity, which increased the disposition index along with weight reduction. In our study, we also observed that the increased insulin sensitivity and reduced insulin demand by DLBS3233 treatment simultaneously led to the enhanced performance of $\beta$-cells, as confirmed by a significant increase of the DIo. Increased DIo basically means augmented $\beta$-cell sensitivity to glucose. However, whether DLBS3233 exerts a direct effect on the pancreatic $\beta$-cells to enhance insulin secretion remains to be studied.

In line with the augmentation of insulin sensitivity, the rate of clearance (MCR) of the glucose from circulation was promoted, at a significantly greater extent than placebo. Nevertheless, the reduction of both 15-minute and 2-hour postprandial glucose levels by DLBS3233 was not significantly different than that of placebo. Yet, as has been elaborately described earlier, the finding that the required 15-minute and 2-hour plasma insulin secretion to maintain the normal level of postprandial glucose was normalized (lowered) was of clinical importance; it consistently indicated an improvement of insulin sensitivity.

Bergman et $\mathrm{al}^{34}$ and Kahn et $\mathrm{al}^{35}$ identified the hyperbolic relationship between insulin sensitivity and secretion. The clinical consequence of the hyperbolic relationship is that increased insulin sensitivity will be compensated by reduction, or downregulation, of $\beta$-cell function, which may be a mechanism to avoid hypoglycemic episodes. ${ }^{36}$ Such an inverse relationship between insulin sensitivity and insulin secretion indicates that it is impossible to judge insulin secretion in a given individual without knowing the ambient insulin sensitivity, since both increases and decreases of insulin sensitivity are associated with compensatory reciprocal changes in insulin secretion.

In brief, the present study demonstrated that the DLBS3233 treatment augmented insulin sensitivity and simultaneously preserved the performance of $\beta$-cell in regulating insulin secretion. The finding also indicated a more effective utilization of insulin by both the liver and peripheral tissues.

We also noted that even though preservation or improvement of $\beta$-cell performance did not occur in placebo group, the insulin sensitivity index (HOMA-IR) was better than the corresponding baseline. The improvement observed in placebo group was possibly attributed to the lifestyle education given to all study subjects during their participation in the study. Lifestyle changes have been proven to delay the progression of IGT to type-2-diabetes. ${ }^{37}$ However, nonadherence to the lifestyle modification for a long period is a major constraint. Therefore, the use of pharmacological therapy, such as DLBS3233, is likely to offset, at least in part, the adverse impacts of non-adherence to lifestyle changes.

About one-third of subjects in DLBS3233 and placebo groups had dyslipidemia, but all had been adequately treated before screening. Therefore, at study entry, the average triglyceride levels of both groups were within the normal range. However, since the insulin resistance was markedly improved with DLBS3233, it was not surprising that a substantial reduction of triglyceride level from baseline was still observed in that group, after 8 and 12 weeks of treatment. At both time points, the reduction of triglyceride level was in favor of DLBS3233.

The findings of this study were consistent with the results of our previous study in insulin-resistant Wistar rats. ${ }^{20}$ The augmentation of insulin sensitivity found in this study can be explained by the action of DLBS3233 in modulating the expression of genes associated with insulin signaling and sensitivity, such as peroxisome proliferators-activator receptor (PPAR)- $\gamma$ and PPAR- $\delta$. In vitro studies with 3T3-Swiss-Albino 
preadipocyte cells showed that stimulation of insulin-signaling transduction by DLBS3233 occurred through the promotion of tyrosine phosphorylation of the insulin-receptor-substrate and upregulation of the expression of phosphatidylinositol3-kinase, PPAR- $\gamma$, PPAR- $\delta$, and glucose transporter-4 at the mRNA level. ${ }^{20,21}$ Activation of PPAR- $\gamma$ and PPAR- $\delta$ by DLBS3233 leads to a series of beneficial metabolic effects on glucose and lipids, suggesting that the product possesses the potential capacity to decrease the incidence of insulin resistance-associated diseases.

Interestingly, we found that DLBS3233 was associated with lowered systolic and diastolic BPs. The mechanism underlying the beneficial effect of DLBS3233 on BP is probably associated with the reduced plasma insulin level and improvement of insulin resistance. It has been widely known that insulin resistance, through a complex physiological interaction with hyperinsulinemia makes an independent contribution to the elevation of BP. ${ }^{38}$ Therefore, improvement in insulin sensitivity will produce a certain reduction in $\mathrm{BP}$, independent of other factors. ${ }^{39}$ Other drugs that improve insulin sensitivity also demonstrated their effects in lowering BP, such as rosiglitazone, ${ }^{39}$ pioglitazone, ${ }^{18}$ and metformin. ${ }^{40}$ The data suggest that along with its virtues on glucose metabolism, DLBS3233 might also provide protection against the development of cardiovascular disease in prediabetic subjects. Whether or not DLBS3233 has direct effects on the vascular system remains to be studied.

With respect to the safety parameters, the reductions in serum ALT and alkaline phosphatase observed with DLBS3233 were all not clinically significant, indicating the safety of treatment, with a trend of protective effect on the liver. A slight increase of the level of serum creatinine observed at the end of treatment with DLBS3233 was still far below the ULN, and the increment was not clinically significant either. This result indicates the safety of the product to renal function.

No serious or severe vascular-related adverse events occurred in either group during the study. Even edema which was commonly found with use of insulin sensitizers was not found with DLBS3233 treatment. Significant reduction of body weight from baseline was observed in both groups, but still, there was no significant difference between groups. Other than appendicitis which was unlikely to have causal relationship with the study product, all adverse events were mild in severity. All adverse events were completely resolved by the end of study.

Limitations of the study are acknowledged. First, we had limited control of the implementation of lifestyle modification during the study, where only lifestyle education and motivation were provided on a regular basis. Variations in the implementation of lifestyle modification might interfere with study results. However, employing random allocation in the study should ensure the equal distribution between groups, of adherent and non-adherent subjects to lifestyle modification. In addition, such a situation more resembles the real situation in community. The second limitation is that the duration of this study was too short for us to evaluate the ultimate goal of treating IGT subjects, that is, the prevention of conversion to type-2-diabetes. However, this study may serve as a sound ground to justify a larger outcome research with a longer duration of treatment and more refined study design to evaluate the risk reduction of type2-diabetes by DLBS3233 treatment in prediabetic subjects and to confirm the real benefits of DLBS3233 treatment in prediabetes.

\section{Conclusion}

This study demonstrated that DLBS3233 treatment at the dose of 50-100 mg once daily was promisingly efficacious in improving insulin sensitivity and preserving the performance of $\beta$-cells. The findings are vital in the attempt to prevent IGT conversion to overt diabetes. The product was also very well tolerated without unfavorable effects on then cardiovascular system, such as weight gain and edema.

\section{Acknowledgments}

This work was funded by Dexa Medica. The authors express their deepest gratitude to the study subjects who participated in the study. They also gratefully appreciate the assistance of Liana W Susanto, MBiomed, Dexa Medica, in the data analysis as well as in the preparation of the draft manuscript.

\section{Author contributions}

All authors contributed toward data analysis, drafting and critically revising the paper and agree to be accountable for all aspects of the work.

\section{Disclosure}

The authors report no conflicts of interest in this work.

\section{References}

1. Barr EI, Zimmet PZ, Welborn TA, et al. Risk of cardiovascular and all-cause mortality in individual with diabetes mellitus, impaired fasting glucose and impaired glucose tolerance: The Australian Diabetes, Obesity, and Lifestyle Study (Aus Diab). Circulation. 2007;101:2682-2689.

2. American Diabetes Association. Diagnosis and classification of diabetes mellitus. Diabetes Care. 2014;37(Suppl 1):S81-S90.

3. Matfin G, Pratley RE. Advances in the treatment of prediabetes. Ther Adv Endocrinol Metab. 2010;1:5-14. 
4. DeFronzo RA, Abdul-Ghani MA. Preservation of $\beta$-cell function: the key to diabetes prevention. J Clin Endocrinol Metab. 2011;96:2354-2366.

5. Manaf A. Management of prediabetes. In: Proceedings of Scientific Conference XI of Internal Medicine. Padang: Department of Internal Medicine, Andalas University; 2009:1-16.

6. Shin JA, Lee JH, Kim HS, Choi YH, Cho JH, Yoon KH. Prevention of diabetes: a strategic approach for individual patients. Diabetes Metab Res Rev. 2012;28 Suppl 2:79-84.

7. Moutzouri E, Tsimihodimos V, Rizos E, Elisaf M. Prediabetes: to treat or not to treat? Eur J Pharmacol. 2011;672(1-3):9-19.

8. Abdul-Ghani MA, Tripathy D, DeFronzo RA. Contribution of $\beta$-cell dysfunction and insulin resistance to the pathogenesis of impaired glucose tolerance and impaired fasting glucose. Diabetes Care. 2006;29: 1130-1139.

9. DeFronzo R, Ferrannini E. Insulin resistance: a multifaceted syndrome responsible for NIDDM, obesity, hypertension, dyslipidemia, and atherosclerotic cardiovascular disease. Diabetes Care. 1991;14:173-194.

10. Wajchenberg BL. $\beta$-Cell failure in diabetes and preservation by clinical treatment. Endocr Rev. 2008;28:187-218.

11. Tuomilehto J, Lindström J, Eriksson JG, et al. Prevention of type-2diabetes mellitus by changes in lifestyle among subjects with impaired glucose tolerance. N Engl J Med. 2001;344:1343-1350.

12. Kitabchi AE, Temprosa M, Knowler WC, et al. Role of insulin secretion and sensitivity in the evolution of type-2-diabetes in the Diabetes Prevention Program. Effects of lifestyle intervention and metformin. Diabetes. 2005;54:2404-2414.

13. Ramachandran A, Snehalatha C, Mary S, et al; for the Indian Diabetes Prevention Programme (IDPP). The Indian Diabetes Prevention Programme shows that lifestyle modification and metformin prevent type-2-diabetes in Asian Indian subjects with impaired glucose tolerance (IDPP-1). Diabetologia. 2006;49:289-297.

14. Knowler WC, Fowler SE, Hamman RF, et al; Diabetes Prevention Program Research Group. 10-Year follow-up of diabetes incidence and weight loss in the Diabetes Prevention Program Outcomes Study. Lancet. 2009;374:1677-1686. Erratum in: Lancet. 2009;374:2054.

15. Phung OJ, Baker WL, Tongbram V, Bhardwaj A, Coleman CI. Oral antidiabetic drugs and regression from prediabetes to normoglycemia: a meta-analysis. Ann Pharmacother. 2012;46:469-476.

16. Chiasson JL, Josse RG, Gomis R, Hanefeld M, Karasik A, Laakso M; for the STOP-NIDDM Trial Research Group. Acarbose for prevention of type-2-diabetes mellitus: the STOP-NIDDM randomized trial. Lancet. 2002;359:2072-2077.

17. Ramachandran A, Snehalatha C, Mary S, Mukesh B, Bhaskar AD, Vijay V. The Indian Diabetes Prevention Programmme shows that lifestyle modification and metformin prevent type-2-diabetes in Asian Indian subjects with impaired glucose tolerance (IDPP-1). Diabetologia. 2006; 49:289-297.

18. DeFronzo RA, Tripathy D, Schwenke DC, et al; for the ACT NOW Study. Pioglitazone for diabetes prevention in impaired glucose tolerance. NEngl JMed.2011;364(12):1104-1115. Erratum in: NEnglJMed. 2011;365:189.

19. Armato J, DeFronzo RA, Abdul-Ghani M, Ruby R. Successful treatment of prediabetes in clinical practice: targeting insulin resistance and $\beta$-cell dysfunction. Endocr Pract. 2012;18:342-350.

20. Tandrasasmita OM, Wulan DD, NailufarF, Sinambela J, Tjandrawinata RR. Glucose-lowering effect of DLBS3233 is mediated through phosphorylation of tyrosine and upregulation of PPAR- $\gamma$ and GLUT-4 expression. Int J Gen Med. 2011;4:345-357.

21. Nailufar F, Tandrasasmita OM, Tjandrawinata RR. DLBS3233 increases glucose uptake by mediating upregulation of PPAR- $\gamma$ and PPAR- $\delta$ expression. Biomed Prev Nutr. 2011;1:71-78.

22. Tjandrawinata RR, Suastika K, Nofiarny D. DLBS3233 extract, a novel insulin sensitizer with negligible risk of hypoglycemia: a phase-I study. Int J Diabetes Metab. 2011;21:13-20.
23. Suastika K, Saraswati R, Dwipayana P, Nugrahini NE, Tjandrawinata RR. A preliminary study of DLBS3233, a bioactive extract of Lagerstroemia speciosa and Cinnamomum burmanii, in newly diagnosed type-2diabetes. Study report. Denpasar: Department of Internal Medicine, University of Udayana; 2011.

24. Bonora E, Targher G, Alberiche M, et al. Homeostasis model assessment closely mirrors the glucose clamp technique in the assessment of insulin sensitivity. Diabetes Care. 2000;23:57-63.

25. Utzschneider KM, Prigeon RL, Faulenbach MV, et al. Oral disposition index predicts the development of future diabetes above and beyond fasting and 2-h glucose levels. Diabetes Care. 2009;32:335-341.

26. Stumvoll M, Van Haeften TW, Fritsche A, Gerich A. Oral glucose tolerance test indexes for insulin sensitivity and secretion based on various availabilities of sampling times. Diabetes Care. 2001;24: 796-797.

27. Stumvoll M, Mitrakou A, Pimenta W, et al. Use of the oral glucose tolerance test to assess insulin release and insulin sensitivity. Diabetes Care. 2000;23:295-301.

28. Diabetes Prevention Program Research Group. The prevalence of retinopathy in impaired glucose tolerance and recent-onset diabetes in the Diabetes Prevention Program. Diabetes Med. 2007;24:137-144.

29. Ziegler D, Rathmann W, Dickhaus T, Meisinger C, Mielck A. Prevalence of polyneuropathy in pre-diabetes and diabetes is associated with abdominal obesity and macroangiopathy: the MONICA/KORA Augsburg Surveys S2 and S3. Diabetes Care. 2008;31:464-469.

30. Kahn SE. The relative contributions of insulin resistance and beta cell dysfunction to the pathophysiology of type 2 diabetes. Diabetologia. 2003;46:3-19.

31. Ferrannini E, Gastaldelli A, Miyazaki Y, Matsuda M, Mari A, DeFronzo RA. Beta-cell function in subjects spanning the range from normal glucose tolerance to overt diabetes: a new analysis. $J$ Clin Endocrinol Metab. 2005;90:493-500.

32. Gastaldelli A, Ferrannini E, Miyazaki Y, Matsuda M, DeFronzo RA. Beta-cell dysfunction and glucose intolerance: results from the San Antonio metabolism (SAM) study. Diabetologia. 2004;47:31-39.

33. Guldstrand M, Ahrén B, Adamson U. Improved b-cell function after standardized weight reduction in severely obese subjects. Am J Physiol Endocrinol Metab. 2003;284:E557-E565.

34. Bergman RN, Ider YZ, Bowden CR, Cobelli C. Quantitative estimation of insulin sensitivity. Am J Physiol Endocrinol Metab. 1979;236: E667-E677.

35. Kahn SE, Prigeon RL, McCulloch DK, et al. Quantification of the relationship between insulin sensitivity and beta-cell function in human subjects. Evidence for a hyperbolic function. Diabetes. 1993;42: 1663-1672.

36. Ahren B, Pacini G. Importance of quantifying insulin secretion in relation to insulin sensitivity to accurately assess beta cell function in clinical studies. Eur J Endocrinol. 2004;150:97-104.

37. McAuley KA, Williams SM, Mann JI, et al. Intensive lifestyle changes are necessary to improve insulin sensitivity: a randomized controlled trial. Diabetes Care. 2002;25:445-452.

38. Ferrannini E, Natali A, Capaldo B, Lehtovirta M, Jacob S, Yki-Järvinen H. Insulin resistance, hyperinsulinemia, and blood pressure: role of age and obesity. European Group for the Study of Insulin Resistance (EGIR). Hypertension. 1997;30:1144-1149.

39. Raji A, Seely EW, Bekins SA, Williams GH, Simonson DC. Rosiglitazone improves insulin sensitivity and lowers blood pressure in hypertensive patients. Diabetes Care. 2003;26:172-178.

40. Landin K, Tengborn L, Smith U. Treating insulin resistance in hypertension with metformin reduces both blood pressure and metabolic risk factors. J Intern Med. 1991;229:181-187. 


\section{Publish your work in this journal}

Drug Design, Development and Therapy is an international, peerreviewed open-access journal that spans the spectrum of drug design and development through to clinical applications. Clinical outcomes, patient safety, and programs for the development and effective, safe, and sustained use of medicines are a feature of the journal, which has also been accepted for indexing on PubMed Central. The manuscript management system is completely online and includes a very quick and fair peer-review system, which is all easy to use. Visit http://www.dovepress.com/testimonials.php to read real quotes from published authors.

Submit your manuscript here: http://www.dovepress.com/drug-design-development-and-therapy-journal 